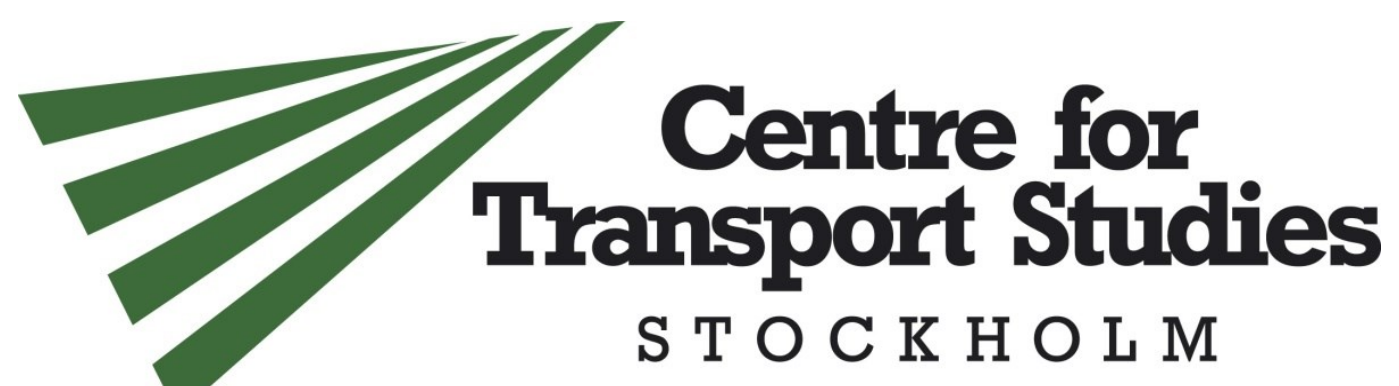

\title{
Land-use impacts in transport appraisal
}

\author{
Maria Börjesson - CTS/KTH ${ }^{1}$ \\ Daniel Jonsson - CTS/KTH \\ Svante Berglund - CTS/WSP \\ Peter Almström - CTS/WSP
}

CTS Working Paper 2013:32

\begin{abstract}
Cost-Benefit analysis (CBA) is sometimes criticized for not taking account of induced demand due to planning policy or relocalization triggered by large infrastructure investments. There is also a notion among planers and decision makers that accounting for these effects can underestimate the relative merits of rail investments. In this paper we explore if induced demand from relocalization triggered by an infrastructure investment have any significant impact on the CBA outcome. A second aim is to investigate the robustness of the relative CBA ranking of rail and road investments with respect to the general planning policy in the region 25 years ahead. We use a large-scale integrated land-use and traffic model calibrated for the Stockholm region. We find that the induced demand from relocalization triggered by infrastructure investments has a very limited impact on the CBA outcome. This result is largely due to the fact that the population that relocates over 20-30 years is limited in comparison to the total population. Moreover, the uncertainty in the CBA outcome, and in particular the relative ranking of rail and road investments, caused by uncertainties in future land-use policies is limited. As expected, however, the CBA outcome of rail investments is to a larger extent dependent on stronger planning policy than road investments. The results underscores that the planning policy in the region have a considerably stronger impact on accessibility and total car use than individual road or rail investments. Only the largest road investment, a second bypass in the region, induces car use of the same magnitude as the impact of the planning policy in the region.
\end{abstract}

Keywords: Cost-Benefit Analysis, Transport planning, Land-use planning

JEL Codes: D61, R41, R42, C25, J22

Centre for Transport Studies

SE-100 44 Stockholm

Sweden

www.cts.kth.se

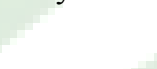





\title{
Land-use impacts in transport appraisal
}

\author{
Maria Börjesson - CTS/KTH ${ }^{1}$ \\ Daniel Jonsson - CTS/KTH \\ Centre for Transport Studies, Royal Institute of Technology, SE-100 44 Stockholm \\ Svante Berglund - CTS/WSP \\ Peter Almström - CTS/WSP \\ Centre for Transport Studies, WSP Analysis \& Strategy
}

\begin{abstract}
Cost-Benefit analysis (CBA) is sometimes criticized for not taking account of induced demand due to planning policy or relocalization triggered by large infrastructure investments. There is also a notion among planers and decision makers that accounting for these effects can underestimate the relative merits of rail investments. In this paper we explore if induced demand from relocalization triggered by an infrastructure investment have any significant impact on the CBA outcome. A second aim is to investigate the robustness of the relative CBA ranking of rail and road investments with respect to the general planning policy in the region 25 years ahead. We use a large-scale integrated land-use and traffic model calibrated for the Stockholm region. We find that the induced demand from relocalization triggered by infrastructure investments has a very limited impact on the CBA outcome. This result is largely due to the fact that the population that relocates over 20-30 years is limited in comparison to the total population. Moreover, the uncertainty in the CBA outcome, and in particular the relative ranking of rail and road investments, caused by uncertainties in future land-use policies is limited. As expected, however, the CBA outcome of rail investments is to a larger extent dependent on stronger planning policy than road investments. The results underscores that the planning policy in the region have a considerably stronger impact on accessibility and total car use than individual road or rail investments. Only the largest road investment, a second bypass in the region, induces car use of the same magnitude as the impact of the planning policy in the region.
\end{abstract}

Keywords: Cost-Benefit Analysis, Transport planning, Land-use planning

\footnotetext{
${ }^{1}$ Corresponding author: maria.borjesson@abe.kth.se
} 


\section{INTRODUCTION}

The transport and land-use systems are mutually dependent on each other in the transportation-land-use cycle (Kelly, 1994). This is, however, seldom taken into account in in transport Cost-Benefit Analysis (CBA). Swedish and British guidelines for infrastructure appraisal (Department for Transport, 2009; Swedish Transport Administration, 2012) for instance, discuss land-use effects only very briefly. The purpose of this paper is to explore to what extent future land-use changes induce bias and uncertainty in the CBA outcome. The importance of land-use impacts in appraisal were identified as key challenge at International Transport Forum (Worsley, 2011)

Land-use assumptions made in appraisal could induce bias or uncertainty in the CBA outcome for two reasons, and we analyze both in this paper. First, the future land-use pattern will depend on the general planning policy over a period of 20-30 years ahead in the region, i.e. to what extent the future planning strive to high public transit accessibility and concentration of new housing. The uncertainty in future planning policy is genuinely uncertain; and this may thus induce uncertainty in the CBA outcome. Second, the evaluated investment itself could have impact on the future land-use and thereby on the travel demand. We denote the latter effect induced demand and land-use impacts.

Uncertainty in CBA outcome can mean many things, and it is usually the uncertainty in the ranking of many investments that are most relevant for policy applications. In the latest Swedish investment plan process, complete CBAs was carried out for 480 investments, in order to compare the relative merits of the investments. One of the hypotheses that we test in this paper is that future landuse policy is of significant importance when CBA is used to rank rail and road investments against each other. We expect that a stronger planning policy, more focused on high densities and transit accessibility, tend to favor rail relative to road investments. Another hypothesis is that induced demand from land-use changes increases the net benefit for rail investments more than road investments. This could be the case since negative externalities (congestion, emissions and accidents) arise from induced car demand and use of transit infrastructure is more dependent on a structured land-use. In summary, this paper investigates if uncertainty in planning policies and not accounting for induced land-use effects could induce a significant bias in relative CBA ranking of investments in general and of rail and road investments in particular.

Criticism of CBA includes bias and uncertainty induced by omitted effects, errors or uncertainty in input assumptions, valuations and interpersonal compensability (Hansson, 2007; Mackie \& Preston, 1998) but the literature quantifying uncertainties in CBAs is still limited. de Jong et al. (2007) review the sources of uncertainty in prediction of travel demand and add to the literature by comparing the level of uncertainty in travel demand due to model inputs and model errors using the Dutch national model. Applying Monte Carlo simulation they find that the former often induces the largest uncertainty in travel demand.

Ashley (1980) and Zhao and Kockelman (2002) explore the uncertainty in model output due to various model inputs in a transport and land-use model, 
finding that uncertainty is likely to inflate over model steps except in the traffic assignment step, because larger transport demand leads to more congestion and reduced demand. Pradhan and Kockelman (2002) find that outputs of the travel demand model is less variable than outputs of the land-use model, because traffic system seeks equilibrium. Moreover, input variables with cumulative effects, such as growth rates induced larger uncertainty in the outcome than other variables. Other studies have found that uncertain socioeconomic forecasts are a significant source of uncertainty (Harvey \& Deakin, 1996; Rodier \& Johnston, 2002; Thompson, Baker, \& Wade, 1997)

Short-term and medium-term behavioural responses to new infrastructure, such as trip frequency, route, mode choice and car ownership are well established and taken into account in standard transport CBA. Long-term spatial reallocation of household and work places could potentially also be important due to relative changes in accessibility inducing additional demand for the transport investment (Goodwin \& Noland, 2003; Hills, 1996; Litman, 2007; Noland, 2001; SACTRA, 1999). Smart Growth advocators argue that public transit investment in this way can help to achieve higher density, while new highway investments tend to lead to the opposite, i.e. more urban sprawl (Bernick \& Cervero, 1997; Newman \& Kenworthy, 1989). Litman (2007) and Noland (2001) hypothesize that employees and households tend to relocate at larger distances from the city in response to highway capacity expansions, increasing VMT (Vehicle Miles Travelled) over and above the increase due to the short-term responses.

Using Australian data, Newman and Kenworty (1988) find that increased average car speeds decreases fuel efficiency in the long run through land-use changes in the entire urban area. Rodier $(2001 ; 2002 ; 2004)$ show that landuse changes induced by highway investments accounts for about $50 \%$ of the increases in travel demand due to the new investments. Marshall and Grady (2005) find, on the contrary, that land-use impact have little effects on travel in cases of rapid population growth and limited road capacity because congestion constrain the urban sprawl in any case. Condor and Lawton (2002) find that the need for new transport investments are overestimated if not taking land-use effects into account because planning policy could be a substitute for investments. Cervero and Kockelman (1997) finds that compact development in terms of high density, pedestrian oriented transport systems and land-use diversity and in the San Francisco Bay Area reduces both trip frequency and motorized travel significantly, which may indicate a reduced benefit for road investments. The varied conclusions from these studies may be caused by different land-use and congestion conditions. Different investments have also different functions in the transport system.

In this paper we apply a large-scale integrated land-use and traffic model calibrated for the Stockholm region and evaluate six rail and road investments in the Stockholm region. Some of them primarily affect local travel and others have a more systemic impact, affect accessibility in large parts of the region. The impacts of future land-use policies are investigated by performing cost-benefit analyses of each investment under three different planning policy scenarios implemented in the land-use model for a period of 25 years (2006-2030): one 
where the planning supports high density and the influence of accessibility to public transit is strong, one where the support for high density and accessibility to public transit is weak, and one in between following current trends.

The impact of induced demand is estimated by simulating to land-use patterns over the period 2006-2030, one in which the investment (for which the CBA is carried out) is assumed to have been introduced in 2006 and one in which it has not. The impact of induced land-use changes on the CBA outcome is then calculated by using different land-use patterns in the traffic forecast model in the build and no-build scenario.

In Section 2 we describe the models in use. In Section 3 we describe the method including experimental setup, the scenario assumptions and description of investments. Section 4 contains the results, and in Section 5 we discuss results. Section 6 concludes.

\section{MODEL SYSTEM}

\subsection{The model system}

We use an integrated land-use and transport model estimated and calibrated for the Stockholm region. The transport model consists of a nested logit demand model including trip generation, mode and destination choice which is linked to a network assignment model. Both the transport model and the land-use model works on a zone level. Each zone includes typically less than 2000 inhabitants.

The transport model is run iteratively with a land-use model. The accessibility from the transport model in each zone, measured as log-sum from the commuting trip model, is fed into the land-use model. The land-use model then assigns workplaces and people to single and multifamily houses into the different zones and feed the land-use back into the traffic model in the next step of iteration. The land-use model is run with a time step of five years, but the transport model is only run for the years 2005, 2020 and 2030.

The share of single and multifamily houses in the county is given exogenously. Annual numbers of migrants to the Stockholm region, and number of existing households that relocate, are also given exogenously. The land-use model gives the number of inhabitants by type of housing (single and multifamily), age and sex in each zone as output. This new population is fed into the models for car ownership and license holding, which together forms the data set that goes into the transport model in the next step of iteration. Car ownership has a large impact on travel demand and is highly dependent on type of housing, income and demography.

The land-use model is a balance between a demand and supply. The supply side is modeled as follows. The lot size is flexible in the land-use model but has a lower bound set by planning restrictions. The model assumes that some land cannot be built on at all, e.g. for natural, cultural, or military reasons and areas close to roads etc. In built up areas the model allows for some additional densification at a slow pace. In some old areas in the city center and areas with very high density no additional growth is allowed. In areas that are pointed out 
by planning authorities as development areas the model allows faster development.

The demand for housing is governed by the indirect utility function formulated as:

$$
u_{i, k}=\beta_{p} a_{p i}+\beta_{c} a_{c i}+\gamma_{k} z_{i}+\delta_{k} d_{i}+Q_{i},
$$

where $u_{i, k}$ is the utility of land-use of type $k$ (single or multifamily housing or work places) in land-use zone i. $a_{p i}$ and $a_{c i}$ are the accessibilities to work places measured as the log-sum from the commuting trip model) with public transit and car, respectively, in zone $i . z_{i}$ is the local accessibility, represented by the population density of zone $i$, and $d_{i}$ measures crowding, represented by a convex function of the population density of zone $i$. The parameter $\gamma_{k}$ is positive, capturing the benefit of increased local accessibility as population density increases, and the parameter $\delta_{k}$ is negative, representing the disutility of increased crowding. The combined effect of $\gamma_{k}$ and $\delta_{k}$ is that utility to live in the zone increases with population density up to a certain density, but above this density the utility instead declines with population density. The term $Q_{i}$ includes local features of zone $i$, such as proximity to water and higher education etc. The demand for workplaces is governed by an indirect utility function identical to eqn (1), but where $a_{p i}$ and $a_{c i}$ are the accessibilities to the work force, also measured as the log-sum from the commuting trip model.

Crowding parameters $\gamma_{k}$ and $d_{i}$ are important, since they determine the demand for more dense/sparse residential areas, i.e. the tendency for urban sprawl. The impact of the crowding parameters, however, is moderated by planning regulations, present in the model, sets an upper limit for densities. Moreover, all the parameters $\gamma_{k}$ and $d_{i}$ and $\beta$ can be calibrated to represent stronger or weaker planning policies. In this study these parameters will be varied to model different land-use policies, see further section 3.2.

\section{METHOD}

As mentioned in the introduction this paper investigates two different issues. In the first analysis, described in section 3.1, we explore to what extent the landuse changes triggered by an investment induce new demand for the investment, and thereby the resulting CBA outcome. In the second analysis, described in section 3.2, we explore to what extent the uncertainty in the general planning policy in the region, and thereby in the future land-use, induce uncertainty in the CBA outcome. In both analyses we simulate the land-use from 2006-2030 under different assumptions of the transport infrastructure (in section 3.1) and of the planning policy in the region (in section 3.2). During 2006-2030 the population in the Stockholm region is in all cases assumed to grow annually by $1 \%$, such that the population increases $28 \%$ over the 25 years that we model.

The six rail and road investments that are analyzed are described in section 3.3. All cost benefit calculations in this paper applies 2030 as forecast year. The benefits are assumed to increase by $2 \%$ per year due to traffic increase. We assume that all investments are opened 2020, have an economical life of 60 
years and the discount rate is 3.5\%. A more detailed description of the CBA methodology is included in section 3.4.

\subsection{Induced demand}

In this analysis, only two investments are analyzed; one large road and one large rail investment. The road investment is the Stockholm bypass, which has a profound effect on the traffic system and is the largest investment in Stockholm since the 1960's (there is already a decision to build this bypass). The rail investment is a commuter rail line that connects the north eastern parts of the Stockholm county to the national and regional rail network and the metro system (section 3.3 describes these investments further).

The localization of households and workplaces in the forecast year 2030 is simulated over the period 2006-2030. Two land-use patterns are simulated for each analyzed investment, one in which the analyzed investment has been introduced in 2006 and one in which it has not. The impact of the induced landuse changes is then calculated by assuming different land-use patterns in the build and no-build scenario in the transport model, as illustrated in Figure 2. In case A, the land-use pattern simulated without the analyzed investment is applied in the transport model both in the build and the no-build scenario. In case $B$, the induced land-use effect from the investment is taken into account: different land-use scenarios are assumed in the built scenario and in the nobuilt scenario. In case $\mathrm{C}$, the induced land-use effect is accounted for by assuming the land-use simulated with the investment in the transport model in the build as well as the no-build scenario.

Case A is predominant in practice, primarily because it is expensive to create alternative land-use scenarios for each investment. If the transport and land-use mode was perfectly consistent (so that all benefits on the transport market appeared in the utility function of the land-use model), if the CS was computed in the land-use model, and if there was no externalities in the transport or landuse markets, the CS in A would be biased against the investment since the landuse is adapted to the no-build scenario, and not to the built scenario. The CS of C would be biased in favor of the investment, since the land-use pattern is adapted to the investment. However, there are several reasons why these results would not hold in the present analysis.

First, we do only compute the benefits in the transport market, implying that the benefits arising from changes in the attractiveness of origin and destination (terms 3-5 in eqn (1)) will be neglected (see further discussion below). Second, the land-use and transport model is not perfectly consistent, because only the accessibility for commuting trips governs the location choice and commuting tips constitute less than half of the trips. Third, even if induced land-use would increase the total benefit for a commuter, it may also induce negative externalities in terms of congestion and emissions. For these reasons it cannot be a priori determined how the net benefit of cases $A, B$ and $C$ will be ranked.

If the land-use remains unchanged, the CS is the logsum from the transport model, and can be approximated with the rule-of-a-half $(\mathrm{RoH})$, which is computed as: 


$$
C S=\sum_{i, j, m} \frac{1}{2}\left(T_{i j m}^{0}+T_{i j m}^{1}\right)\left(c_{i j m}^{1}-c_{i j m}^{0}\right),
$$

where $T_{i j m}$ is number of trips and $c_{i j m}$ is the generalized transport cost in the OD relation $i j$ by mode $m$.

However, when land-use is changed in response to some new infrastructure eqn (2) omits changes in origin attractiveness (see Minken et al. (2003) and Martínez \& Araya (2000) for a mathematical derivation of $\mathrm{RoH}$ in an integrated land-use and transport model). We do, however, still use (2) as an approximation of the CS, because changes in origins are relatively small. Changes in attractiveness destinations due to relocation of workplaces and households are taken into account in the CS calculation.

\section{Land use}
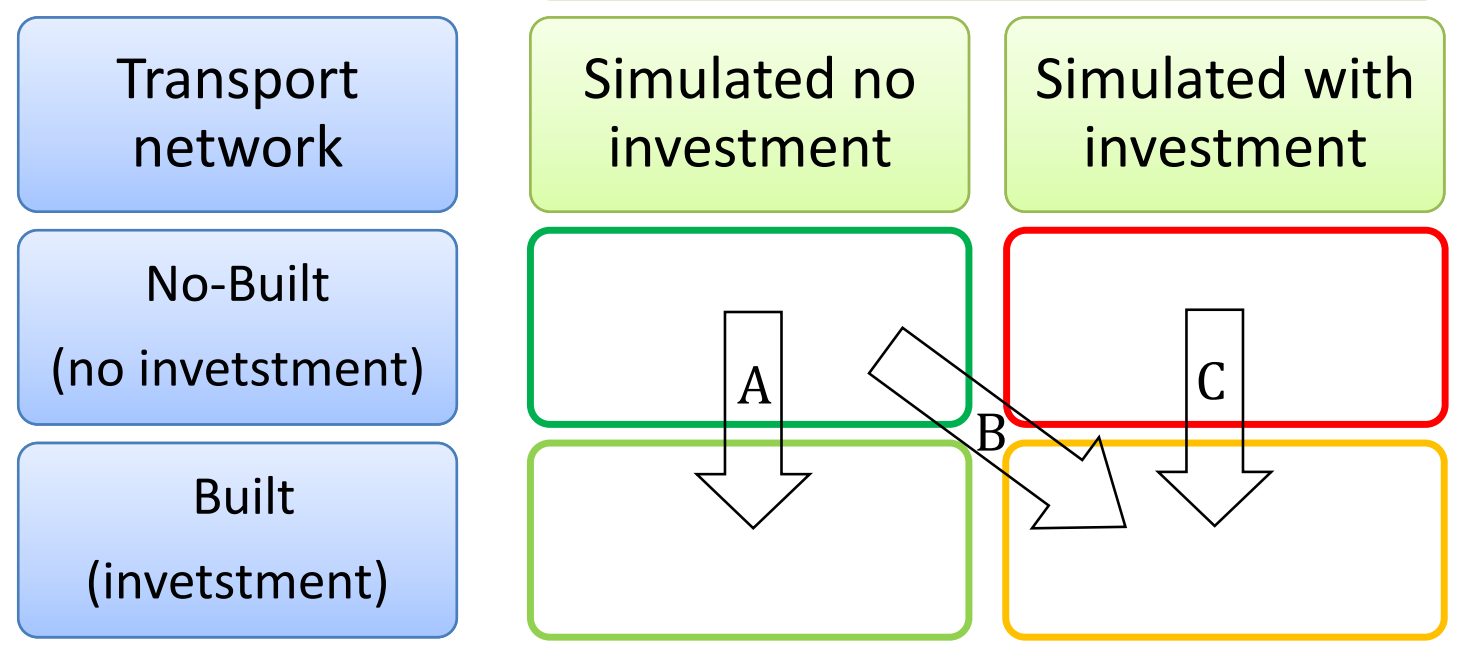

Figure 1. In $A$ and $C$ the land-use is the same in both base scenario and investment case, with $A$ simulated with a no investment transport system and $B$ a network with the investment present. In $B$ the base case has a non-investment land-use and the investment case an investment-adjusted land-use.

\subsection{Uncertainty in planning policy}

The next part of the analysis, we neglect the effect of land-use changes induced by the investments. Instead we concentrate on the robustness of a CBA ranking with regard to the general planning policy in the region.

Three different planning policies are constructed and implemented in the landuse model: Central, Trend and Peripheral. These policies were used when authorities are evaluating and forecasting the regional development plan $^{2}$ for Stockholm for 2010, which is an outcome of a negotiation between the regional level and the municipalities.

\footnotetext{
${ }^{2}$ Regional plans in Sweden are not binding for the municipalities rather a guidance they have agreed on. The national infrastructure plans use the land use in the regional plan.
} 
For each of the six investments described in the following section, we perform one cost-benefit analysis for each planning policy. We use the rule-of-a-half defined in (2) for all CS calculations. Since the land-use remains unchanged between the build and the no-built scenario in the transport network in this analysis, the origin and destination attractiveness remains unchanged and do not affect the CS calculation.

The planning policies are implemented in the land-use model by modifying parameters in the utility function, eqn (1), and the exogenously given global share of single and multifamily housing in the region. The utility function is modified with respect to the tolerance for housing density $\left(\delta_{k}\right)$ and sensitivity for public transit and car accessibility $\left(\beta_{p}\right.$ and $\left.\beta_{c}\right)$.

Table 1 describes the land-use pattern in 2030, resulting from the three planning policies. The Trend policy is calibrated to reproduce current long-term trends in land-use pattern, in terms of how the population density declines with distance to the central business district, tolerance for housing density, and demand for public transit accessibility. The population growth in the regional center is assumed to be $30 \%$, which reflects the current trend. $58 \%$ of the additional population (the population increase) is assumed to move into multifamily houses, which also reflects the trend in the region over the past 30 years.

\begin{tabular}{|c|c|c|c|c|c|c|c|}
\hline & \multirow{2}{*}{$\begin{array}{c}\text { Percent of } \\
\text { Population } \\
2010\end{array}$} & \multicolumn{3}{|c|}{$\begin{array}{c}\text { Percent of additional } \\
\text { population 2010-2030 }\end{array}$} & \multicolumn{3}{|c|}{ Percent of population 2030} \\
\hline & & Central & Trend & Peripheral & Central & Trend & Peripheral \\
\hline $\begin{array}{l}\text { Regional } \\
\text { center }\end{array}$ & 46 & 59 & 30 & 14 & 48 & 44 & 41 \\
\hline $\begin{array}{l}\text { Inner } \\
\text { suburb }\end{array}$ & 25 & 21 & 36 & 38 & 24 & 26 & 27 \\
\hline $\begin{array}{l}\text { Outer } \\
\text { suburb }\end{array}$ & 29 & 20 & 34 & 48 & 28 & 30 & 32 \\
\hline
\end{tabular}

Table 1. Population distribution in 2010 and in the scenarios studied.

In the Central policy $78 \%$ of the additional population is assumed to move into multifamily houses and the tolerance for high density is considerable. A higher weight is assigned to the accessibility with public transit $\left(\beta_{p}\right)$, and almost $60 \%$ of the growth in population takes place in the regional center.

In the peripheral policy we assume that a minority, $27 \%$, of the new housing units are multifamily houses. A higher weight is assigned to the accessibility with $\operatorname{car}\left(\beta_{c}\right)$ and the largest part of the immigrant population move into the peripheral parts of the region, and the population growth in the regional center in only $14 \%$.

The realism of the different scenarios could be put in the perspective of historical development trends and current plans. The regional development plan for Stockholm for 2010 is a mix of the Central and Trend planning policy, with regard to regional distribution of population and density. The peripheral 
policy differs most from the current regional plan $^{3}$ but since the municipalities are not bound to the regional plan this scenario is still not unrealistic. The freedom of a decentralized planning system can be used and are used by some municipalities to depart from regional plans which in some cases results in a more dispersed settlement pattern.

\subsection{Investments}

We carry out cost-benefit analyses for six rail and road investments in the Stockholm region, shown on the map in Figure 2. The investments were selected from infrastructure objects previously evaluated by the national road and rail administration, when constructing the national investment plan. Using previously studied objects provides us with realistic projects and cost estimates. From the list of projects we based our selection on four criteria 1) both rail and road projects should be represented, 2) projects of different size, 3) projects spread across the region and 4) estimates of construction costs should be available.

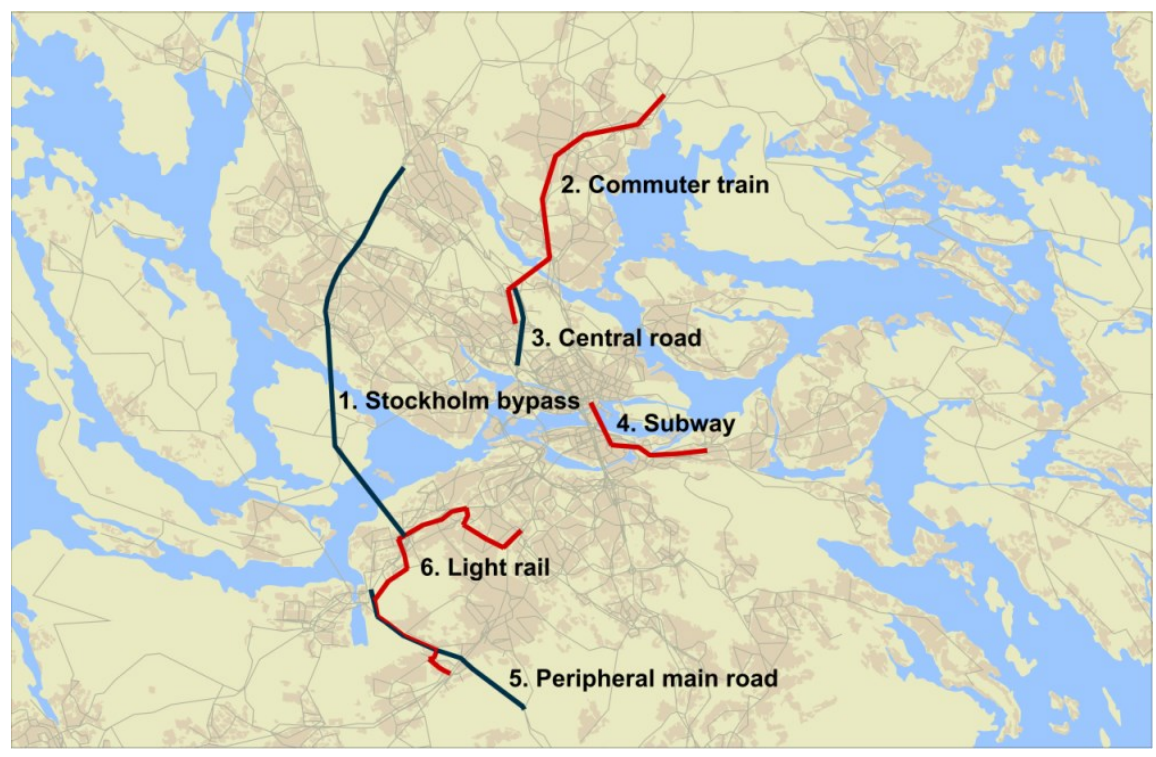

Figure 2. Map shoving the six rail and road investments in the study. Number 1,3 and 5 are road investments while number 2, 4 and 6 are rail investments.

Investment 1, the Stockholm bypass, is a motorway bypass that is planned to go west of Stockholm, mainly in a tunnel. Currently, there is only one highly congested bypass to the west of the inner city, E4/E20 that connects the northern and southern part of Stockholm. The investment cost is estimated to approximately $€ 2.6$ billion $^{4}$. Investment 2 is a commuter rail line that connects the north eastern parts of Stockholm County to the national and regional rail network and the metro system. The investment cost is estimated to $€ 1.2$ billion. Investment 3 is a central road tunnel that increases the capacity of the current major north-south highway arterial with an investment cost of around $€ 0.8$ billion. Investment 4 is a Metro line from central Stockholm to going to Nacka

3 Regional Utvecklingsplan för Stockholm 2010.

http://www.tmr.sll.se/Global/Dokument/publ/2010/RUFS10_hela.pdf

${ }^{4}$ Here and throughout the paper we have converted SEK to Euro using a conversion rate of 10 SEK/€. 
located east of the city center. The investment cost is approximated to $€ 0.8$ billion. Investment 5 is a peripheral main road that provides an improved eastwest connection in the southern part of Stockholm County. The investment cost is approximated to $€ 0.26$ billion. Investment 6 is a light rail line that connects Flemingsberg (a major healthcare and educational center with a regional and commuter train station) to the large shopping area of Kungens kurva, two of the current metro lines and the commuter train station of Älvsjö. The investment cost is estimated to about $€ 0.7$ billion. All investment costs are given in the price level of $2006^{5}$.

\subsection{CBA details}

The CBA in this paper follows in general Swedish guidelines for infrastructure appraisal (Swedish Transport Administration, 2012).

\section{Investment}

For the purpose of comparison between the investments we have assumed that the whole investment cost is paid in the year 2019, that the investment is in use from 2020 and that the economic life of the investments is 60 years. Remember that the benefits are assumed to increase by $2 \%$ per year due to traffic increase over this period and the discount rate is 3.5\%. The marginal cost of public funds (MCPF) is equal to 1.3 .

\section{Consumer surplus (CS)}

The consumer surplus is calculated using RoH defined by (2), with values of time from Swedish guidance. They amount to 8.7 (commuting) and 5.9 (other purposes) $€ / h$ for car and 6.9 (commuting) and 5.3 (other purposes) $€ / h$ for public transit in-vehicle time. Public transit auxiliary and waiting time is weighted 1.5 of in-vehicle travel time. Commercial traffic has a value of time of $39 € / \mathrm{h}$.

Distance dependent cost for cars is $0.18 € / \mathrm{km}$. Commercial transport consists of both heavy and light trucks, and is assumed to on average have a distance based cost of 2.5 times a private car.

\section{Producer surplus (PS)}

The cost of operating a public transit line is based on the number of departures per day and the occupancy rate. The occupancy rate is not the realised occupancy rate, but is fixed per vehicle type. Costs for rolling stock and maintenance are included, but not infrastructure re-investment. Different costs are assigned to buses, light rail, commuter rail, and the metro.

\section{Externalities}

Externalities are computed link by link, with emission rates and fuel consumption differentiated by link type (but not by congestion level). The Swedish guidelines differentiate values depending on location (urban, rural,

\footnotetext{
${ }^{5}$ The costs are taken from decision supports, see Swedish Traffic administration www.trafikverket.se
} 
suburban etc.). For simplification, we have assumed that the entire Stockholm county is an urban area.

\section{Government}

Government revenues are affected by fuel taxes, congestion charges paid, and VAT paid for public transit fares.

\section{RESULTS}

\subsection{Benefits of induced relocation effects}

The effect on location choice due to the two investments, Stockholm bypass and the Commuting train, is very similar and relatively small. Approximately 2530000 people and 15-20 000 workplaces in the Stockholm County relocate in response to both investments ${ }^{6}$. This accounts for about $5 \%$ of the population and workplace growth in Stockholm County and for about 1-1.5\% of the total population. For both investments, about $20 \%$ of the people and workplaces that relocate change municipalities.

\section{VMT}

The increase in total VMT in response to the introduction of the Stockholm bypass in the county is very similar in case A (land-use adapted to the traffic system in the no-build scenario, both in the build and no-build scenario), B (land-use are assumed to adapt to the traffic system between the build and the no-build scenario) and C (land-use adapted to the traffic system in the build and no-built scenario), implying increase in VMT due to the induced land-use changes is small. The increase in VMT is $3.68 \%$ in case A and $3.84 \%$ in both B and C.

Not surprisingly, the Commuting train has a much smaller impact on the VMT in the county (the impact of this investment is more local than the bypass), but does also differ more between scenarios: $0.07 \%$ in A, $0.42 \%$ in B and $0.10 \%$ in C. The larger VMT reduction in case $\mathrm{B}$ indicates that the more transit oriented land-use induced by the Commuting train reduces VMT even if this train is taken out of the network.

The results above are obtained by assuming the Trend planning policy, but the VMT differ very little and with the same pattern in the Central and Peripheral planning policies.

\section{CBA}

The full cost benefit analyses are shown in Table 2. For the Stockholm bypass, the CS is very similar in all cases: they differ less than $1 \%$ between $\mathrm{A}, \mathrm{B}$ and $\mathrm{C}$. Recall that the difference between them only reflect difference in accessibility and not the total welfare, since the benefit from changes in attractiveness in origins are left out of the analysis. Welfare effects from changes in attractiveness of destinations (due to relocation of workplaces and households) are included,

\footnotetext{
${ }^{6}$ Calculated at traffic zone level.
} 
but differ only in B where the land-use in the built and no-build case. From the limited number of households that change location in response to the bypass, compared to the benefit per capita in the county arising in the transport market, the effect on welfare from changes in attractiveness of origins are most likely small compared to the net benefit in the transport market.

\begin{tabular}{|c|c|c|c|c|c|c|}
\hline & Stockholm & bypass & & Commutir & g train & \\
\hline CBA $^{7}$ & $A$ & B & $\mathrm{C}$ & A & B & C \\
\hline $\begin{array}{l}\text { Reduced travel times } \\
\text { Car }\end{array}$ & 28216 & 28455 & 28596 & 142 & 1122 & -30 \\
\hline $\begin{array}{l}\text { Reduced travel cost, } \\
\text { Car }\end{array}$ & 22102 & 22194 & 22241 & 17 & 57 & 18 \\
\hline $\begin{array}{l}\text { Reduced travel times } \\
\text { Transit }\end{array}$ & 11256 & 11287 & 11310 & 8514 & 8582 & 8612 \\
\hline $\begin{array}{l}\text { Destination } \\
\text { attractiveness }\end{array}$ & 0 & 488 & 0 & 0 & 649 & 0 \\
\hline Freight & 29532 & 29579 & 29580 & 46 & 374 & 17 \\
\hline Total CS & 91106 & 92002 & 91727 & 8719 & 10784 & 8617 \\
\hline Running cost & -2095 & -2101 & -2077 & -3861 & -4787 & -3859 \\
\hline Ticket revenues & 256 & 269 & 261 & 1012 & 1921 & 1006 \\
\hline Total PS & -1839 & -1832 & -1817 & -2848 & -2866 & -2853 \\
\hline $\mathrm{CO} 2$ & -4741 & -4797 & -4770 & 100 & 339 & 92 \\
\hline Traffic safety & -2661 & -2768 & -2694 & 180 & 687 & 179 \\
\hline Other & -453 & -458 & -456 & 10 & 33 & 9 \\
\hline Total externalities & -7855 & -8023 & -7920 & 289 & 1059 & 280 \\
\hline Congestion Charges & -20332 & -20371 & -20376 & 0 & 0 & 0 \\
\hline VAT tickets & 64 & 67 & 65 & 253 & 480 & 252 \\
\hline Fuel tax & 9530 & 9643 & 9589 & -201 & -681 & -186 \\
\hline Summa budgeteffekter & -10738 & -10661 & -10722 & 52 & -201 & 66 \\
\hline Net benefit & 70673 & 71487 & 71268 & 6212 & 8776 & 6110 \\
\hline Investment cost & 25000 & 25000 & 25000 & 9000 & 9000 & 9000 \\
\hline MCPF & 8052 & 8050 & 8045 & 3555 & 3560 & 3556 \\
\hline BCR & 2.3 & 2.4 & 2.4 & 0.2 & 0.4 & 0.2 \\
\hline
\end{tabular}

Table 2. CBA under different assumptions of induced land-use changes.

The other components of the CBA, producer surplus (PS), externalities, and government budget effects, do not show any systematic differences between the A, B and C. The increased cost from externalities in cases B and C are balanced by higher revenues of the government from fuel taxes, since the externalities (except congestion) arising from car traffic to some extent is internalized. The benefit-cost ratios $(\mathrm{BCR})^{8}$ are almost the same in case $\mathrm{A}, \mathrm{B}$ and $\mathrm{C}$.

\footnotetext{
${ }^{7}$ Definitions from Table 1.

${ }^{8}$ This ratio is here defined as the net benefit (including the marginal cost of public funds) divided by
} 
For the Commuter train, both BCR and CS are approximately 20\% higher for case $\mathrm{B}$ than $\mathrm{A}$ and $\mathrm{C}$. The benefit from reduced externalities, are more than $70 \%$ higher in case B. Again this indicates that the land-use induced by the Commuting train per se increases accessibility and reduces car use, even if the Commuting train is taken out of the network. It is possible that the induced land-use also changes the attractiveness of origins and destinations, so that the total welfare in cost-benefit analysis B may be smaller or larger. The additional welfare effect on changes in land-use may be larger in case of the Commuter rail line compared to the bypass; approximately the same number of households has changed location in the land-use patterns induced by these investments, compared to the land-use simulated without the investments, but the accessibility benefits of the bypass are more than ten times higher than the benefits of the Commuting train.

Still, accessibility benefits and reduction in externalities are significantly higher if the induced land-use effects are taken into account. Still the BCR changes only from 0.2 to 0.4 .

\subsection{Investments and land-use policy}

In the next analysis we neglect the effect of land-use changes triggered by the investments and concentrate on the robustness of a CBA ranking with regard to the general planning policy in the region over 26 years.

\section{VMT}

The bars in Figure 3 shows the percentages increase in VMT in the Stockholm County for all six investments evaluated using the three different land-use policy scenario. The bars show the effect on the VMT relative to the Trend planning policy scenario in the base case than includes none of the six investments. The three leftmost bars show that in VMT is about $4 \%$ lower in the Central scenario and about 4\% higher in the Peripheral scenario in the base case.

The total VMT differ in general more between land-use scenarios than between infrastructure investment scenarios. It is only the Stockholm bypass that gives an increase in VMT of the same magnitude as the difference between the planning policy scenarios; about $4 \%$ (the effect is slightly smaller in the Central land-use policy scenario).

The total number of trips made with public transit relative to the base case is shown in Figure 4. Again the land-use policy has a substantially larger effect on number of public transit trips than any of the investments. Relative to the Trend scenario, the number of trips is about 4\% lower in the Peripheral scenario and about $4 \%$ higher in the Central scenario. The metro increases the number of public transit trips $0.5 \%$ in the county and the committing train increases the transit trips with $0.4 \%$. The road investment has almost no effect on the transit use because the cross-elasticity between car and public transit is low. The

the investment and running cost. Swedish appraisal uses the net present value ratios (NPVR), which equals the $B C R+1$. 
changes in transit passenger kilometers are similar to the change in number of transit trips, but the effect is slightly higher on passenger kilometers $(+0.9 \%)$ from the Commuting train, because this investment carries longer trips.

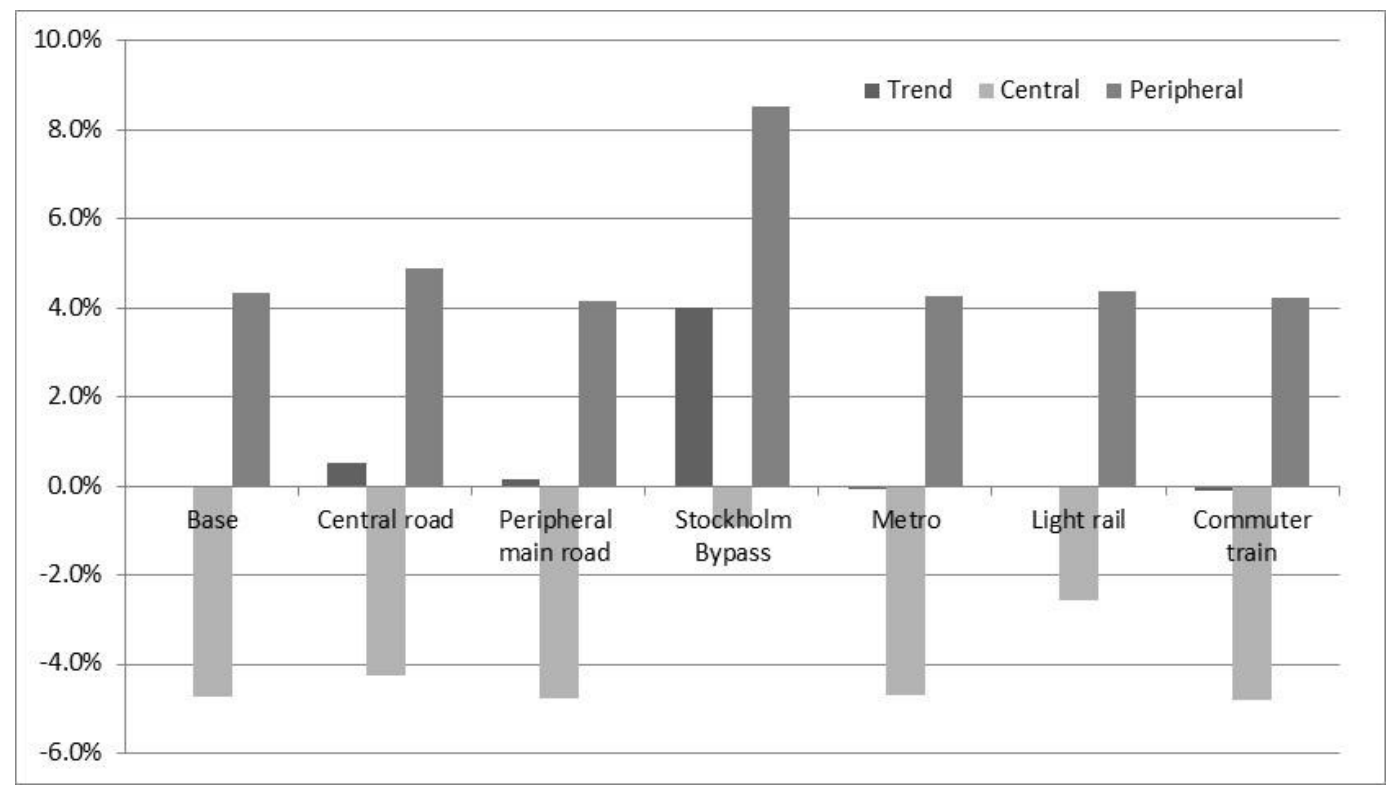

Figure 3. Relative changes in total annual VMT in Stockholm County. Comparisons are made with the Trend base case.

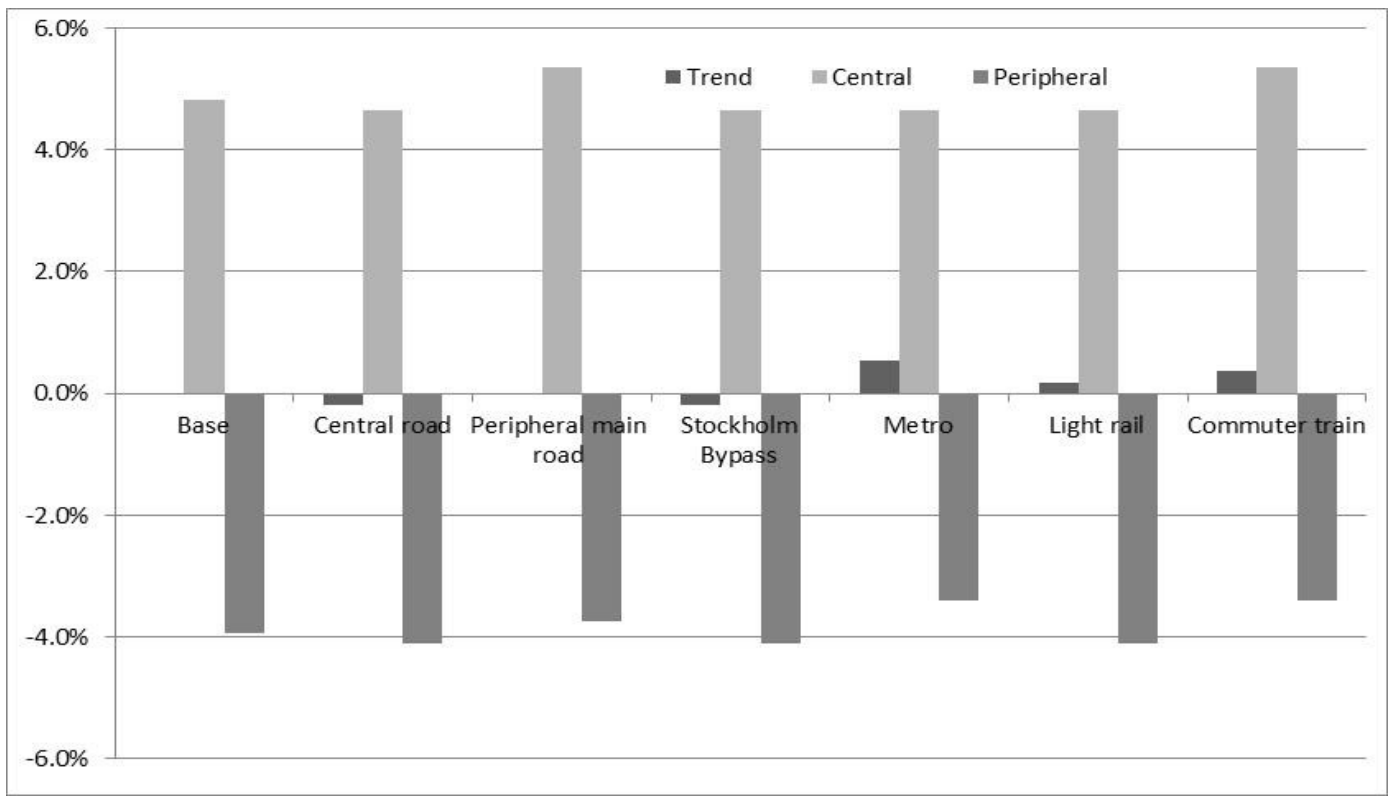

Figure 4. Relative changes in number of public transit trips in Stockholm County. Comparisons are made with the Trend base case.

\section{CBA}

Next we turn to how the consumer surplus and BCR for the investments differ with assumed land-use-policy. Table 3 shows the annual CS for the six investments, for each of the three land-use scenarios. The table shows also the change in CS relative to the Trend planning policy and the change in total net benefit of the investments (including all effects such as produced surplus, external effects and budget effects) relative to the Trend scenario. 
There are only small differences (less than 5\% for all investments) in CS for the investments between the Trend and the Peripheral planning policy. Comparing the Trend and the Central planning, the differences are larger primarily for the Peripheral main road and the Metro. The effect on the total net benefit is sometimes higher and sometimes lower than the effect on the CS, but of the same magnitude.

Not surprisingly the benefit of the Peripheral main road reduces in the Central planning policy, because this policy reduces car use in general and car use in the periphery in particular. However, the benefit is higher in the Trend planning policy than the Peripheral because congestion and density become larger with the former. The Central road investment does also give a higher benefit with the Trend policy than with the Peripheral policy because congestion becomes less severe in the latter. The benefit with the Central policy is almost as large as in the Trend policy, even if there is in general less car use in the latter, because the congestion in the central city is similar.

The Stockholm bypass increases accessibility in most parts of the County, as opposed to the other investments that increase accessibility more locally. For this reason the benefit is less sensitive to different planning policies; the difference in CS between the planning policies is within $5 \%$. As expected the benefit is slightly higher for the Peripheral policy with highest VMT in the county and slightly lower for the Central policy with lowest VMT in the county.

The benefit of the Commuter rail line does not at all differ between the planning policies due to two factors acting in different directions. On the one hand the benefit increases in the more transit oriented planning policies, but on the other hand it also increases in more peripheral policies since this is a peripheral investment, see Figure 2. The Light rail is also a peripheral transit investment and has therefore the lowest benefit in the Central policy. The benefit is about the same with the Peripheral policy as with the more transit oriented Trend policy, again because this is a rather peripheral investment.

The Metro is a more central transit investment, and the benefit of the Metro is therefore highest with the Central policy. The difference in benefit between the Trend and Peripheral policy is small, but the benefit of the Metro is surprisingly slightly higher in the latter. The Metro increases the transit accessibility in the eastern peripheral parts of the County (along the coast) where the population increases in Peripheral planning policy.

The main conclusion from these results is that the benefit is fairly stable across future planning policies. Moreover, the benefit of rather peripheral transit investments does not in general increase with a more transit and high density oriented planning policy. More peripheral transit investments will gain from a less centralized land-use, because the effect on accessibility is relatively local.

Similarly, benefit of road investments does not as a rule increase in a more peripheral land-use, in particular not investments aimed at increasing capacity. In a denser land-use pattern congestion will increase, increasing the benefit of higher road capacity particular in central locations. However, the benefit of large road investments that increases accessibility in the region will general 
increase with planning policies that focus less on high density and transit accessibility.

\begin{tabular}{|l|r|r|r|r|r|r|r|}
\hline & Trend & \multicolumn{2}{|c|}{ Central } & \multicolumn{2}{|c|}{ Peripheral } & $\begin{array}{c}\text { CS } \\
\text { relative } \\
\text { to } \\
\text { Central } \\
\text { relative } \\
\text { to } \\
\text { Central } \\
\text { benefit } \\
\text { relative } \\
\text { to } \\
\text { Central }\end{array}$ & $\begin{array}{c}\text { Net } \\
\text { benefit } \\
\text { relative } \\
\text { to } \\
\text { Central }\end{array}$ \\
\hline $\begin{array}{l}\text { Central } \\
\text { road }\end{array}$ & 37 & 37 & $-2 \%$ & $2 \%$ & 36 & $-5 \%$ & $-2 \%$ \\
\hline $\begin{array}{l}\text { Periphe } \\
\text { ral main } \\
\text { road }\end{array}$ & 14 & 11 & $-20 \%$ & $-17 \%$ & 14 & $-3 \%$ & $-4 \%$ \\
\hline $\begin{array}{l}\text { Stockho } \\
\text { lm } \\
\text { Bypass }\end{array}$ & 322 & 312 & $-3 \%$ & $-4 \%$ & 329 & $2 \%$ & $2 \%$ \\
\hline Metro & 27 & 29 & $9 \%$ & $11 \%$ & 28 & $4 \%$ & $4 \%$ \\
\hline $\begin{array}{l}\text { Light } \\
\text { rail }\end{array}$ & 16 & 15 & $-6 \%$ & $-9 \%$ & 16 & $1 \%$ & $1 \%$ \\
\hline $\begin{array}{l}\text { Commu } \\
\text { ter rail } \\
\text { line }\end{array}$ & 30 & 31 & $1 \%$ & $3 \%$ & 30 & $0 \%$ & $0 \%$ \\
\hline
\end{tabular}

Table 3. Annual consumer surplus (CS) [M€/year] for the six investments, for the three land-use scenarios. Relative differences of CS and total net benefit of the investments in percent between Central and Trend and Peripheral, respectively.

The BCR for the six investments, given each of the three planning policies, are shown in Table 4 . Only the road investments indicate a net benefit $(B C R>1)$. There are only small differences across planning policies and the pattern is consistent with Table 3. The ranking of investments are stable, except that in the Central planning policy the Central road has a higher BCR than the Peripheral road, and this order is reversed in the other planning policies.

Finally we interpret the results in the light of the ranking of objects in the Swedish national investments plan 2010-2020. In the investment plan process, complete CBAs were carried out for 480 investments, 417 road investments and 63 rail investments. These investments can be divided into approximately equally sized segments based on their BCR: i) $11 \%$ of the investments had a BCR above 3 ii) 19\% had a BCR in the range of $2-3$, iii) $18 \%$ had a BCR in the range of $1.5-2$, iv) $25 \%$ had a BCR in the range of $1-1.5$, vi) $15 \%$ in had a BCR in the range of $0.7-1$ and v) $11 \%$ had a BCR in the range of $-4-0.7$.

If the benefit of the Peripheral main road with a BCR of 1.4 (in Trend) changed $\pm 10 \%$ due to errors in the predicted future planning policy, the BCR would increase to 1.5 or decrease 1.2. The BCR of the Metro would change from 0.5 to 0.6 or 0.4 and the BCR of the Stockholm Bypass would change from 2.5 to 2.8 or 2.2 if the benefits changed $\pm 10 \%$. Hence, an uncertainty interval of about $20 \%$ $( \pm 10 \%)$ of the benefits due to uncertainty in future planning policy (which is a larger change of net benefit between planning policies than for any of the 
investments in Table 4) changes the ranking of the 480 objects to a limited extent; all investments stays within the same segment of BCR.

\begin{tabular}{lrrr}
\hline Investment & \multicolumn{1}{c}{ Trend } & \multicolumn{1}{c}{ Central } & \multicolumn{1}{c}{ Peripheral } \\
\hline Central road & 1.2 & 1.2 & 1.1 \\
Peripheral main road & 1.4 & 1.1 & 1.3 \\
Stockholm Bypass & 2.5 & 2.4 & 2.6 \\
Metro & 0.5 & 0.6 & 0.5 \\
Light rail & 0.1 & 0.1 & 0.1 \\
Commuter rail line & 0.3 & 0.3 & 0.3 \\
\hline
\end{tabular}

Table 4 Benefit-cost ratio (BCR) for the six investments assuming the three different land-use policy scenarios

\section{DISCUSSION}

Land-use forecasts are confoundedly uncertain, usually more uncertain that than traffic forecasts. The transport system is to a larger extent than the housing market an outcome of forces working in different directions seeking equilibrium. Moreover housing supply is uncertain because it is not only developed by market forces, but also by planners and politicians, whose decisions are difficult to forecast and model. Long-term integrated land-use and investment planning is not the normal case in Sweden or in most other countries. Normally the state or region fund infrastructure investments while municipalities have the power over the land-use planning. A classical problem is that politicians in municipalities in the periphery are less concerned with congestion and other externalities within the city center. It is therefore a reassuring result that the CBA rankings seem to be relatively stable with respect to future planning policy and induced demand due to land-use adaptations.

There are several reasons behind this stability. First, the existing demand constitutes the largest part of future demand because land-use patterns changes slowly. Over a period of 25 years the population is forecast to increase $28 \%$ in the region, but the location of the other households remains unchanged. This holds for most mature cities, but may of course be different for investments built in previously very sparsely or unpopulated locations, where existing demand would be limited compared to new demand or demand induced by the investment.

Second, better car accessibility and induced car use does often increase the benefit of road investments, but this is balanced by negative effects in terms of congestion and emissions. Third, most investments are used by many different categories of traffic which are affected in different ways. Forth, the difference in BCR for the investments in a national plan is usually large. Hence, even if the net benefit changes $20 \%$, the effect on the ranking of investments is limited. $20 \%$ is the largest impact of different assumptions of future planning policies or of induced demand that is found for any of the investments in this paper. 
In the introduction we hypothesized planning policies that more strongly focuses on high density and transit accessibility tend to favor rail investments relative to road investments. Even if the benefit of the Stockholm bypass increases slightly in the Peripheral planning policy and decreases slightly in the Central, our results do in general not support such conclusion. One reason is that congestion increases in a denser land-use, which tends to increase the benefit of increased road capacity, in particular road investments central in the region. Another reason is that most of the suggested public transit investments are not located in the central parts of the region, where the transit system is already in place (an exception is the suggested metro extension). The benefit of more peripheral public transit does not increase with a planning strategy promoting centralization and high density.

The induced land-use changes from the largest road investment in Stockholm since the 1960's, the Stockholm bypass, are almost negligible and have almost no effect on the benefit of this investments. One reason is that the bypass increases car accessibility in most parts of the county, so that the relative difference in accessibility between different locations remains rather stable. Note though that this result holds under the assumption that the land-use demand and supply are ruled by market forces. If, however, an investment decision is well integrated with an extensive land-use plan for the concerned area, the outcome could be different from the land-use model forecast. In that case, however, the planned land-use effects could easily be taken into account in the CBA evaluation, since it is known. The point is that large land-use adaptation, structuring or dispersing, cannot be expected just to appear but has to be deliberately planned for.

However, the results are somewhat different in case of the Commuter rail line. The induced land-use adaptation reduces the VMT four times as much as the investment itself and the additional accessibility benefit of the land-use adaptation is approximately $20 \%$ of the benefit of the Commuting train. Note, however, that benefit of the rail line per se does not increase due to the land-use adaptation; the benefit of the induced land-use persists even if the Commuting train would be taken out of the network (after inducing the land-use effects). This result suggests that transit investments indeed do have additional benefits, by increasing demand for denser and more public transit oriented land-use development, as suggested by smart growth advocators (Bernick \& Cervero, 1997; Newman \& Kenworthy, 1989). However, for the reasons discussed above, this impact is not large enough to have any substantial impact on the ranking of investments in a national plan.

The finding from this paper is summed up in Figure 5. The top arrow in the figure indicates that this study gives a rather week support to the hypothesis that road infrastructure, without well-integrated land-use planning, induces either land-use structure or sprawl. The small effects from induced land-use must, however, be seen in the perspective of a mature city that has found its form. The additional accessibility arising from the new investment is in most cases marginal compared to the original accessibility. On the other hand, as indicated by the lower arrow in Figure 5, the land-use achieved by planning 
have an important effect on the function of the traffic system in terms of VMT, congestion and accessibility.

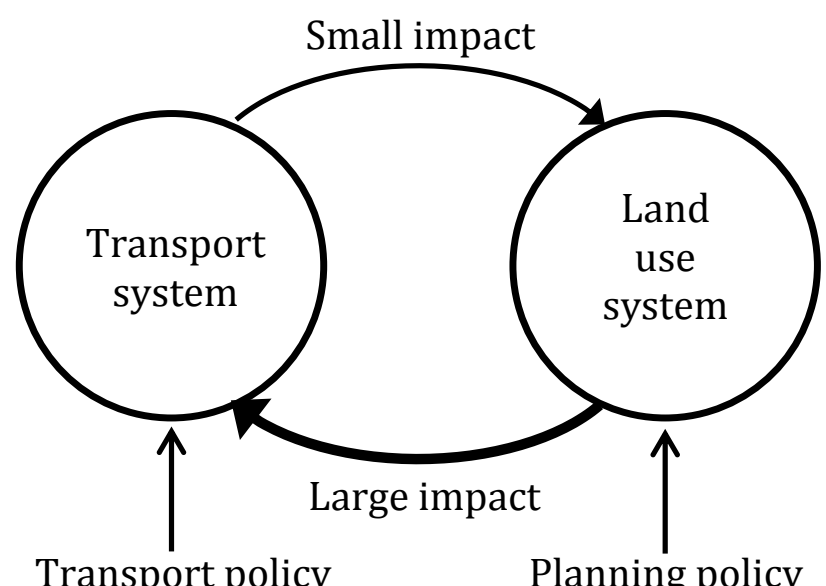

Figure 5 Summary of the results on the impact of the land-use on the transport system and vice versa.

\section{CONCLUSION}

This paper studies whether uncertainty of future planning policy and long-term induced land-use impacts from infrastructure investments, give rise to significant uncertainty in the CBA ranking of investments, for instance in a national plan.

We conclude that the future planning policy does not influence the CBA ranking to any large extent. Moreover, we find no support for the hypothesis that the benefit of rail investments, relative to road investments, is systematically higher if the future planning policy stresses higher density land-use and public transit accessibility. However, our results suggest that the induced land-use from transit investments in fact add a significant reduction of car use and increases the accessibility benefit. However, the magnitude of this effect is still not large enough to change the ranking of investments in a national plan to any significant extent.

Another insight from this paper is that the VMT in a region is to a much larger extent determined by land-use policies than infrastructure investments. This is consistent with the conclusions of Zhao and Kockelman (2002) and Pradhan and Kockleman (2002). Hence, it is the planning strategy, rather than transport investments, that leads to a more car or public transit oriented society.

To summarize, there is little evidence in this study suggesting that it is important to run land-use models in transport appraisal. In case, however, that new settlements are planned as part of integrated land-use and infrastructure projects this should obviously be taken into account, but does not require any land-use modeling. 
Land-use impacts in transport appraisal 


\section{REFERENCES}

Ashley, D. J. (1980). Uncertainty in the context of highway appraisal. Transportation, 9(3), 249-267. doi:10.1007/BF00153867

Bernick, M., \& Cervero, R. (1997). Transit villages in the 21st century. New York: McGraw-Hill. Retrieved from http://trid.trb.org/view.aspx?id=572959

Cervero, R., \& Kockelman, K. (1997). Travel demand and the 3Ds: Density, diversity, and design. Transportation Research Part D: Transport and Environment, 2(3), 199-219. doi:10.1016/S1361-9209(97)00009-6

Condor, S., \& Lawton, K. (2002). Alternative Futures for Tansportation and Land Use-Integrated Models Contrasted with “Trend Delphi"Methods: The Portland Metro Results. Transportation Research Record, 1805, 99-107.

De Jong, G., Daly, A., Pieters, M., Miller, S., Plasmeijer, S., \& Hofman, F. (2007). Uncertainty in traffic forecasts: literature review and new results for The Netherlands. Transportation, 34, 375-395.

Department for Transport. (2009). Department for Transport - Transport Analysis Guidance - WebTAG. Retrieved from http://www.dft.gov.uk/webtag/

Goodwin, P., \& Noland, R. B. (2003). Building new roads really does create extra traffic: a response to Prakash et al. Applied Economics, 35(13), 1451. doi:10.1080/0003684032000089872

Hansson, S.-0. (2007). Philosophical problems in Cost-Benefit Analysis. Economics and Philosophy, 23(2), 163-183.

Harvey, G. W., \& Deakin, E. (1996). Description of the STEP analysis package. DHS, Incorporated. Retrieved from http://www.mtc.ca.gov/maps_and_data/datamart/historic/STEP_Descri ption_Feb1996.pdf

Hills, P. (1996). What is induced traffic? Transportation, 23(1). doi:10.1007/BF00166216

Kelly, E. D. (1994). The Transportation Land-Use Link. Journal of Planning Literature, 9(2), 128-145. doi:10.1177/088541229400900202

Litman, T. (2007). Generated Traffic and Induced Travel. ITE Journal, 71(4), 3847.

Mackie, P., \& Preston, J. (1998). Twenty-one sources of error and bias in transport project appraisal. Transport Policy, 5(1), 1-7. doi:10.1016/S0967-070X(98)00004-3

Marshall, N., \& Grady, B. (2005). Travel Demand Modeling for Regional Visioning and Scenario Analysis. Transportation Research Record: Journal of the Transportation Research Board, 1921(-1), 44-52. doi:10.3141/1921-06

Martínez, F., \& Araya, C. (2000). Transport and land-use benefits under location externalities. Environment and Planning A, 32(9), 1611-1624.

Minken, H., \& Jonsson, D., Shepherd, S., Järvi, T., May, A., Page, M., Pearman, A., Pfaffenbichler, P., Timms, P. and Vold, A. (2003). A. Methodological Guidebook; pro pects. Retrieved from http://www.infra.kth.se/courses/1H1402/Litteratur/pr_del14mg.pdf

Newman, P. W. G., \& Kenworthy, J. R. (1989). Gasoline Consumption and Cities. Journal of the American Planning Association, 55(1), 24-37. doi:10.1080/01944368908975398 
Noland, R. B. (2001). Relationships between highway capacity and induced vehicle travel. Transportation Research $A$, 35(1), 47-72. doi:10.1016/S0965-8564(99)00047-6

Pradhan, A., \& Maria Kockelman, K. (2002). Uncertainty Propagation in an Integrated Land Use-Transportation Modeling Framework: Output Variation via UrbanSim. Transportation Research Record: Journal of the Transportation Research Board, 1805(-1), 128-135. doi:10.3141/180515

Rodier. (2001). Anatomy of induced travel using an integrated land use and transportation model in the Sacramento Region.

Rodier, C J. (2002). Heuristic policy analysis of regional land use, transit, and travel pricing scenarios using two urban models. Transportation research. Part E, Logistics and transportation review, 7(4), 243.

Rodier, C. (2004). Verifying Accuracy of Regional Models Used in Transportation and Air Quality Planning: Case Study in Sacramento, California, Region. Transportation Research Record: Journal of the Transportation Research Board, 1898(-1), 45-51. doi:10.3141/1898-06

Rodier, Caroline J, \& Johnston, R. A. (2002). Uncertain socioeconomic projections used in travel demand and emissions models: could plausible errors result in air quality nonconformity? Transportation Research A, 36(7), 613-631. doi:10.1016/S0965-8564(01)00026-X

SACTRA. (1999). Transport and the Economy, Standing Advisory Committee on Trunk Road Assessment. London.

Swedish Transport Administration. (2012). ASEK 5 - rapporter (Text). Retrieved from http://www.trafikverket.se/Foretag/Planera-ochutreda/Planerings--och-analysmetoder/Samhallsekonomisk-analys-ochtrafikanalys/ASEK---arbetsgruppen-for-samhallsekonomiska-kalkyl-och-analysmetoder-inom-transportomradet/ASEK-5---rapporter/

Thompson, D., Baker, M., \& Wade, D. (1997). Conformity: Long-Term Prognoses for Selected Ozone Nonattainment Areas in California. Transportation Research Record: Journal of the Transportation Research Board, 1587(-1), 44-51. doi:10.3141/1587-06

Worsley, T. (2011). The evolution of London's crossrail scheme and the development of the department for transport's economic appraisal methods. In Discussion Paper 2011-27. Presented at the International Transport Forum (ITF), OECD. Retrieved from http://www.econstor.eu/handle/10419/68827

Zhao, Y., \& Kockelman, K. M. (2002). The propagation of uncertainty through travel demand models: an exploratory analysis. Annals of Regional Science, 36(1), 145-163. 